
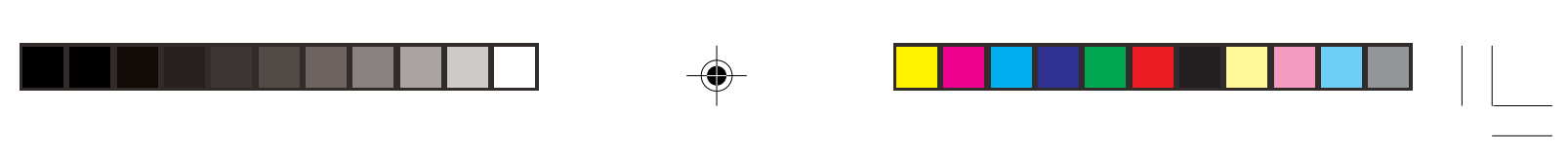

\title{
LEIBNIZ'S THEORY OF BODIES: MONADIC AGGREGATES, PHENOMENA, OR BOTH?
}

\author{
Christina Schneider *
}

\begin{abstract}
RESUMO A concepção leibniziana dos corpos parece ser uma teoria enigmática. Corpos são vistos como agregados de mônadas e como fenômenos bem fundados. Isso deu origem a controvérsias e a discussões intermináveis. Este artigo tenta resolver as aparentes inconsistências por meio de uma reconstrução nova e formalmente inspirada da teoria da Leibniz das mônadas e da percepção, por um lado, e uma (re)formulação mais precisa de seu conceito de harmonia pré-estabelecida, por outro lado. A harmonia pré-estabelecida é modelada basicamente como uma covariação entre o reino monádico e ideal.
\end{abstract}

ABSTRACT Leibniz's conception of bodies seems to be a puzzling theory. Bodies are seen as aggregates of monads and as wellfounded phenomena. This has initiated controversy and unending discussions. The paper attempts to resolve the apparent inconsistencies by a new and formally spirited reconstruction of Leibniz's theory of monads and perception, on the one hand, and a (re-)formulation and precisation of his concept of preestablished harmony, on the other hand. Preestablished harmony is modelled basically as a covariation between the monadic and the ideal realm.

Palavras-chave Leibniz, corpos, metafísica, mônada, harmonia pré-estabelecida

Ludwig-Maximillian-Universität München

KRITERION, Belo Horizonte, $n^{\circ}$ 104, Dez/2001, p.33-48 


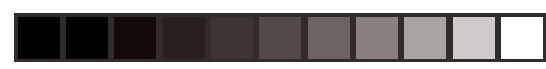

2

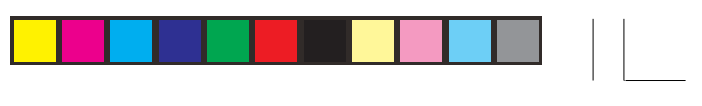

Christina Schneider

Leibniz' theory of bodies gave rise to remarkable interpretational puzzles and controversies. On the one hand, Leibniz claims that bodies are aggregates of monads and, on the other hand, he asserts that bodies are wellfounded phenomena. The two conceptions of bodies are sometimes dubbed as "flatly inconsistent"' ${ }^{1}$. There have been several proposals to reconcile the two approaches. This paper is a new attempt to come to grips with Leibniz' twofold conception of bodies. The resolution of the puzzle is rooted in a reconstruction of Leibniz' theory of monads which give rise to an associated "theory of wellfounded phenomena". It makes use of mathematical methods and claims to be a twenty-century making sense of Leibniz' metaphysical positions. It is somewhat like Strawson's ${ }^{2}$ attempt to reformulate the position of a "hypothetical Leibniz", but, in contrast to Strawson, it is not on behalf of formulating a contrasting theory, but to present a Leibnizian portion of metaphysics worth of being thought about today.

The article is organized as follows: it starts with some general remarks about the leading intuitions. Since there is no hope for a consistent story without making precise Leibniz's conception of wellfounded phenomena and his theory of monads, section 2 is devoted to the theory of (simple) monads. Section 3 is about ideas. Based on the results of section 2 and section 3, section 4 will propose a resolution of the apparent tension between the two concepts of bodies. The upshot will be that the two "conceptions" are two sides of a single coin. The last section summarizes some reflections about whether a Leibnizian position can be endorsed.

\section{Some general remarks}

The puzzle's solution to be proposed is based on several assumptions and intuitions which should be kept in mind and are listed in what follows. First, whatever a body may be otherwise, it is a phenomenon. This assumption is rooted in Leibniz's claim that all that which is (sensually) experienced, either in common life or in the frame of "experimental" science, is a phenomenon. So, for him even space and time, cause and effect are phenomena.

Second, phenomena can be chimerical or wellfounded. That means they may be "true" or "false". Therefore, in the present context, they are attributed only to entities with intellectual capacities, in Leibniz's terms: they are attributed to apperceiving monads only.

1 Adams 1983, p. 218.

2 See Strawson 1959. 

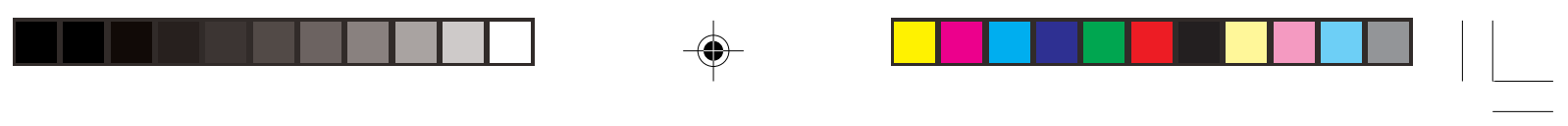

"True" or "false", chimerical or wellfounded, hints to some connection to the monadic realm. Therefore, thirdly, if a phenomena can be chimerical or wellfounded only if "thought about", reflected or apperceived, and if "thinking”, "reflecting”, "apperceiving” deal with ideas, the connection of ideas to the "monadic realm" has to be exploited, too. The clue to the solution is Leibniz's claim that space and time, being phenomenal, are also ideal entities, from which "the real things can not escape," as Leibniz puts it ${ }^{3}$. The coordination of space and time to the monadic realm is taken as a paradigm for the coordination of other ideas to space and time.

The solution of the puzzle of bodies as wellfounded phenomena and as monadic aggregates relies on the explication of phenomena, wellfoundedness and apperception. The explication combines the two great metaphysical realms Leibniz deals with: the monadic world and the ideas in God's mind, as well as idées innées and reflected ideas. The solution hinges crucially on the insight that for Leibniz an idea contemplated by God is strictly both: an intelligible content in God's mind and a constituent of the best of all possible worlds. Virtually, the same holds for idées innées and ideas contemplated by finite beings. Therefore, the "relationship" between ideas and the monadic realm must be explained. The explanation will be a reinterpretation of Leibniz's principle of preestablished harmony, which will make use of the "modern concept" of covariation.

To sum up: If phenomena, wellfoundedness and apperception are explained, the solution of the problem ensues immediately. The explanation of the three topics is embedded in a reconstruction of the connection of the monadic world and the ideal realm.

\section{Monads and perceptions}

Whereas it seems much easier to understand what an aggregate of monads (as a body) could mean, the understanding of phenomena, especially wellfounded phenomena, is much more complicated. Since wellfoundedness indicates a certain rooting in the monadic realm, a reconstruction of monads, perceptions, and the monadic realm will be given. The reconstruction will be rather informal and sketchy here. It presents the minimal assumptions needed to understand wellfounded phenomena. ${ }^{4}$

3 Gerhardt 1965a, IV, p. 569.

4 A detailed account can be found in Schneider 1998 and 1999. 


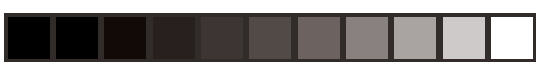

4

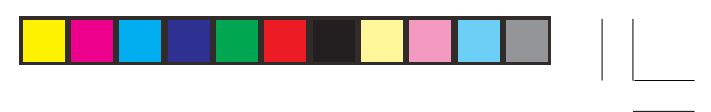

Christina Schneider

\subsection{The monadic realm}

The Monadology starts with characterizing monads as simple and partless, and, therefore, enduring entities. These partless entities nevertheless have qualités. Moreover, without these qualités they would not even be entities. The qualités are called perceptions and in virtue of these perceptions each monad "mirrors" the "world" from their respective situs. "The world", in turn, is not anything over and above the monads, their perceptions and their appetites.

The task of any reconstruction is, therefore, to make explicit the strong entanglement between monads, perceptions and "the world". There is no monad without world and no world without monads. This means: "World" cannot be conceived of as being made up by collecting a heap of ready-made monads, since in that case, before being collected, monads would not have anything to perceive and would not be entities at all. But similarly, "world" cannot be conceived of as a certain sort of preexisting entity in which some monads are placed to perceive it (among other monads), since in that case there had to be some further structure "of the world" to be perceived at all. The main idea of the reconstruction basical for this article is: Monads should turn out to be welldefined substructures of the world, and the world, in turn, should be defineable uniquely by coordinated families of structures, i.e., monads. Further, starting the exposition with monads should come to the same structure, the perceptional-monadic world, as starting with reconstructing the perceptional-monadic world and then working out those substructures which are monads, their perceptions, and their situsses.

Instead of going into details, some guiding and some refused paradigms in making sense of "monads" and "perceptions" will be addressed. Instead of fromal definitions an example, better a "picture", of the monadic world will be given. First, "monads" are not modelled as structureless tiny billard balls or geometrical points. They are structured entities, encompassing in some sense other entities of the same kind. Second, perceptions are not seen, even not remotedly, under the paradigm of sensual experience, faint as it may be. What could be called "sensual experience" belongs to the "phenomenal realm" and is coordinated to special higher monads as are "souls" or "spirits" only.

\subsection{Monads, perceptions and appetite}

The structures that fit the above mentioned entanglement are special families of filters, topological spaces and their neighborhood-filters. Therefore, the monadic world, monads and their perceptions are conceptualized as topological spaces and topological (neighborhood) filters are used: Monads 

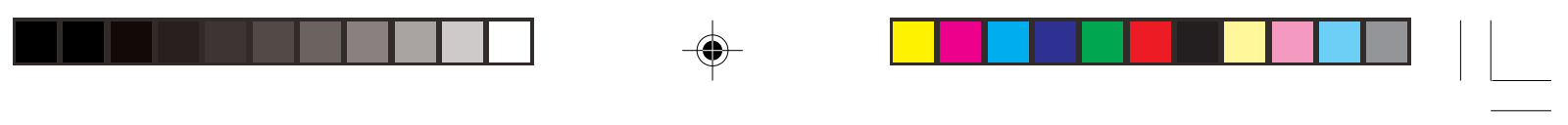

are special filters, the elements of the filters being the respective perceptions. The filters in turn define uniquely the respective situs and, taken together, define uniquely a topological Hausdorff space - the perceptual-monadic world. This topological space has, in turn, the defining filters as its neighborhood filters. Conversely, starting with a topological Hausdorff space, the monadic world, neighborhood filters, the monads and their perceptions, are uniquely defined. There is no topological space without its unique neighborhood filters and no families of a special family of filters without the uniquely associated topological space whose neighborhood filters they are. ${ }^{5}$ In the first place only monads at one instant of their respective histories are regarded; they are called "instanteneous monads". The appetite of monads will be addressed later. For the present purpose, it is sufficient to note that the monadic world is a topological Hausdorff space and the instantaneous monads are the neighborhood filters thereof. The points of the topological space are the (instantaneous) situsses of the monads. Instead of going into formal details, the intuition behind this conception may be visualized as follows: The best known topological Hausdorff space is, perhaps, the Euclidean plane, where the Euclidean distance defines the topology. It is a more specialized topology as needed here, but that does not matter for fixing ideas only. Take one point, $x$ say, of the plane and regard all the circles around that point: $\left\{C_{r}(x):=\{y:|x-y|<r\}: r \in \mathfrak{R}, r>0\right\}$, joining to these circles all sets, which enclose at least one of the circles $C_{r}(x)$; then, one gets the filter of neighborhoods of $x$. Such a filter can be conceived of as an instantaneous monad, the elements of the filter, i.e., the circles and the other sets can be regarded as perceptions. The $x$ can be regarded as the situs of the respective instantaneous monad. To make sense of this identification, note that every neighborhood filter has the whole set, here the wohle Euclidean plane, as its element. This means, each monad perceives the whole world and with it all other monads (other neighborhood filters), but only confusedly. Circles with a smaller radius, or "smaller sets", are distincter perceptions than those with greater radius. The "smaller" circles intersect fewer other monads and distincter perceptions of them. The smaller circles, distincter perceptions, perceive only "neighboring" instantaneous monads, but of these monads, distincter perceptions.

An instantaneous monad is "one" in the following sense: if one would leave out only one set of the filter, i.e., one perception, the remainder would not be a filter/instantaneous monad.

5 For detail, see Kelley 1955. 
The conception of instantaneous monads as neighborhood filters has also extrinsical virtues: It leads to a natural interpretation of Leibniz's conception of space-time, it is the interpretational clue to his "principle of continuitiy" and, as will be shown soon, it gives rise to an interpretation of the wellfoundedness of phenomena.

Keeping these intuitions in mind, one can write the monadic world as ( $W$, $\mathbf{T}$ ), where $\mathbf{T}$ is the topology and the $u \in W$ are the situsses of the respective instantaneous monads The elements are the perceptions of the respective instantaneous monad and may be, as the example with the circles in the Euclidean plane show, more or less confused.

So far, appetite has not been considered. Without going into formal details, the monadic world, getting its structure from instantaneous monads or, if preferring the converse reading, having instantaneous monads as substructures, is not regarded as a "time-slice" where other "time-slices" are needed to complete the history of the monadic world. Instead, the special "series" of instantaneous monads are joined to monads in an ordered way. To be slightly more precise: A monad is an ordered family of intantaneous monads. This is similar to a series or sequence of instantaneous monads, with one important difference: whereas series have atmost countable members, a monad encompasses "as many instantaneous monads as are members in $\mathfrak{R}$ ". This makes it possible to regard perceptual change as "continuous”. Further, monads should not overlap. I.e., two different monads cannot share a perception. Mathematically, this comes to defining appetite by means of a "flow". As a consequence, each monad has its private history. It is rooted in Leibniz' intuition that "time" ("global time") is not a monadic matter, but an ideal or phenomenal entity which has its foundation in the monadic reality, and that time, as physical entity, "presupposes" change, i.e., appetite. ${ }^{6}$

In its simplest version, a flow is a mapping with $\Phi(0, u)=u$ and

The index must not be interpreted as "time". The index, together with the natural order of , indicates the succession of instantaneous monads/perceptions only; moreover, if $\Phi$ is continunous, it indicates a "continuous" succession. A more detailed understanding of "flows" is not necessary now, since related topics are not pursued in this article.

Let $\mathbf{T}$ be the topology defined by the family $\mathbf{W}_{u}$ and a flow defined on it; one can finally define $(W, \mathbf{T}, \quad)$ as the perceptual-monadic world and as a monad - made up from the "succession" of its 

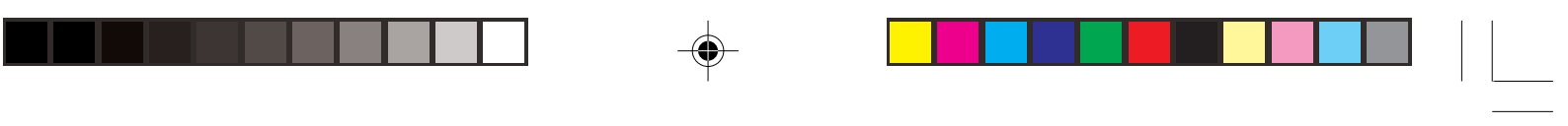

LEIBNIZ'S THEORY OF BODIES: MONADIC AGGREGATES, PHENOMENA, OR BOTH?

[instantaneous] perceptions The instantaneous perceptions may be expressed by:

\section{Ideas}

In Leibniz, "ideas" have a manifold meaning. They figure as instruments of thinking, and as objects or contents of thought, they are what the "real things cannot escape", they are in the mind of God and contemplated by Him. A certain optimal configuration of the ideas in God's mind is qualified as the best possible world and set to existence by Him. For short, sometimes ideas seem to be understood as psychological entities and sometimes as metaphysical/ontological entities. In psychological contexts they are sometimes called "notions", in metaphysical/ontological circumstances they figure sometimes as “concepts”. But, as it were in the Leibnizean corpus, terminology is far from being consistent, even not within small portions of it. In this paper, "ideas" are understood as metaphysical/ontological entities which have ontological import on the monadic world.

The exegetic problem whether Leibniz did endorse a theory of ideas, especially the theory of individuals as complete concepts, in his mature philosophy, whether his theory of monads is in continuity with his complete $W_{\Phi^{u}(t)} \in \mathbf{W}_{\Phi^{u}(t){ }^{c}}$ concept theory of individuals and so on, is not pursued in this article. ${ }^{7}$ Instead, the reconstruction used in this article is based on the insight that from a systematic point of view ideas are necessary to complement the monadic world. So far the structure of the monadic realm is too sparse to do duty to the pretheoretically experienced variety of the "world". For instance, on the basis of monads and perceptions, whether they are conceived of as "abstract" as in the present article, or in a more flamboyant manner as sensual experiences and the like, space and time cannot be understood as it is necessary for theoretical physics, since space and time are ideal entities (as well as phenomenal entities) and the world is (only) "adequate" to them.

There is another reason for attributing ontological import to ideas: In Leibniz's theory of creation they make up the best of all possible worlds, an ideal construction in God's mind and contemplated by Him. This best of all possible worlds is set to existence by God. The question is, what happens with that ideal configuration in God's mind when put to existence. During his lifetime Leibniz saw himself accused of endorsing a sort of Spinozism - the last thing Leibniz liked to be accused of, as Wilson writes. ${ }^{8}$ Leibniz's escape

7 Concerning this topic, see, for instance, Rutherford 1995, p. 148, and passim. 8 See Wilson 1989, p. 89. 
from Spinozism was, as he himself says in a letter to Bourguet of $1714^{9}$, his theory of monads. The question remains: What is the relation between the monadic reality/world and the ideal best of all possible worlds? Is the monadic world a simple copy of it, a homomorphic picture and the best of all possible worlds in God's mind a sort of blueprint? If this were the case, the monadic realm would have to be stuctered like the ideal best of all possible worlds. This, however, is precluded by the sparseness of the monadic world and, if this were not the case, by the architectonic difference between the monadic realm and the ideal realm: the ideal realm is built up combinatorially, primitive ideas are basic and complexer ideas are made up of primitive ones. Further, there is nothing that could match the "mirroring-metaphor" in the ideal realm. "Mirroring" is not atomistic in character, but points to a highly intertwinned realm, articulated as topology in the present context.

The relationship between the monadic and the ideal realm to be presented here is based the on interpretation and precisation of Leibniz's architectonic principle of the "preestablished harmony". Roughly speaking, the architectonic principle of preestablished harmony is fleshed out as a certain sort of covariance or "paralellism". This means: The monadic realm is different from the ideal realm, it is not in God's mind, it is not "ideal" in character, and it is not a simple duplication of ideas. The best of all possible worlds, in turn, stays where it was and as it was in God's mind. For covariation in a way that the "things" cannot escape the ideas, only a very weak structural adequacy between both realms is needed for the present purpose.

\subsection{The ideal realm refined}

The monadic realm was defined as a topological space. This is structure enough. Concerning the structure of the ideal realm, one must remember that ideas can be conveided of as "the intelligible content" of the things to be created by God. They are either simple or complex. The complex ideas are made up of simple ideas in a combinatorial manner.

Individuals figure as complete concepts in the ideal realm. Neglecting in the first step that complete concepts should furnish the intelligible contents for the history of individuals too, they can be understood ("instantaneously") on the line of "maximally consistent" sets of simple ideas and possible worlds are greater compossibilia (possible worlds). Complete concepts are ideal complexities and encode all and everything that an individual is, what happens to it, what it feels and what it thinks, it further encodes all the circums-

9 See Gerhardt 19651a, III, p. 575. 

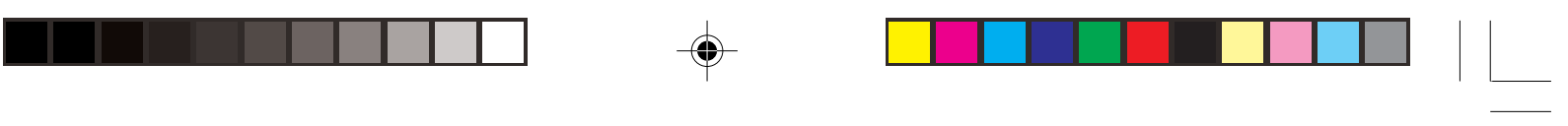

tances of space and time the individual is in. ${ }^{10}$ If one simple and unimportant idea were "lost", the respective individual would be — at best — something else. Therefore, concerning one instant of the history of an individual, the instant complete concept $\Psi(t, c)$ can be regarded as the set

$$
\Psi(t, c)=a_{\Psi, t, c}^{r z} \cup a_{\Psi, t, c}^{s} \cup a_{\Psi, t, c}^{a}
$$

where $a_{\psi, t, c}^{r z}$ stands for the ideas of space and time, it encompasses all ideas expressing its "physical state". Together with the respective instantaneous monad, it can be seen as contributing to the monadic/ideal foundation of stones and billard balls and the like. $a_{\psi, t, c}^{s}$ stands for the sensitive ideas, which encode the sensual states individuals may have, if able to have them. They are not to be confused with physical states. They are what is felt if adequate physical states obtain. Physical and senstive states covary, joined by preestablished harmony. Last not least, $a_{\psi, t, c}^{a}$ stand for apperceptions and must be explained later. The respective sets are disjoint. All three contribute to the fully determinateness of the respective individual. Further, due to what can be called "hyperindividualism", there cannot be two identical but numerically different ideas. Nevertheless, there must be a foundation for what can, for finite thinking subjects, be epistemically, be called "universals", e.g., the intelligible contents for "experienced qualities". The simplest way to do duty to them, is to conceive of them as sets of simple ideas. ${ }^{11}$ If a finite being thinks or speaks of "red", he speaks of a special set comprising all and only different simple but "similar" "red-ideas". The simple "red-ideas", which cannot be differentiated further, can be contemplated only by God. As Leibniz puts it: Finite beings usually are not aware of the simple ideas.

Until now, complete concepts are formulated as intelligble contents for "instantaneous individuals". Therefore, these complete concepts must be joined to ordered families thereof. This can be done, as in the monadic realm, by joining the complete concepts by a flow $\Psi$, say. This flow makes it sure that no historically complete concept can ever share the constituting ideas of another historical complete concept. A historical complete concept, complete concept for short, can now be written as $\{\Psi(t, c): t \in \mathfrak{R}\}$ with

For any $t \in \mathfrak{R}, \Psi(t, c)$ is a member of the instantaneous complete concepts. The flow partitions this set. Let In be the set of instantaneous complete con-

10 See Gerhardt 1965a, II, p. 56.

11 This could be formally refined by using concepts of formal trope theory. In this frame "universals" would be formulated as similarity circles. This would give the ideal realm a finer structure. For the present question, this is not necessary. For a trope theoretic account see Mormann 1995, and for reconstructing the ideal realm Schneider 1999. 
cepts and taking care of the historicity of individuals, the best of all possible world as an ideal composibility can now be written as

3.2 Preestablished harmony between the ideal and the monadic realm

The connection between the monadic and the ideal realm under the paradigm of covariation or "parallelity" may now be expressed as as a mapping: There is a one-to-one and onto mapping from the monadic world $(W, \mathbf{T}$,

) to the ideal realm

This means that there should be instantaneously as many monads as are complete concepts. And further, that there are as many monads as are historical complete concepts. I.e., there are as many individuals/monads in the monadic world as are in the ideal best of all possible worlds. Moreover, the change of a monad within an intervall of length $t$ of its "personal time" should correspond to a succession of length $t$ of its corresponding complete concept. ${ }^{12}$

So far, no topological assumptions are needed for the definitions above. To define the mapping as continuous, however, topology is indispensable. Continuity in this context means: small changes within the historical complete concept should correspond to small changes of the perceptual history. To make the continuity claims precise, a topological structure, based on trope theoretical concepts has to be imposed on In, too. Since this is not needed in the present article, this topic is not problematized. ${ }^{13}$

The covariation of a monad with its historical complete concept means that God, on the one hand, created monads according to the complete concepts in his mind and, on the other hand, created entities different from them and not in his mind.

A fully determined monad, taking into account its whole history and its complete concept , can now be written as:

$$
\left(\mathbf{W}_{\Phi, t, c}, \Psi(t, c), \rho, t \in \mathfrak{R}\right)
$$

\section{Wellfounded Phenomena, monadic aggregates and bodies}

So far, two groups of important distinctions have not been addressed explicitely: On behalf of monads, the difference between simple monads, souls

12 For detail, see Schneider 1999, ch. 4

13 But see Schneider 1998 and 1999. 
and spirits and, concerning ideas, the different sorts of ideas Leibniz speaks of. The monadic world as presented above takes care only of the features common to all monads. Souls have besides perceptions and appetite what Leibniz calls "memory" and a sort of sensitivity. Their intuitive model are (higher) animals. The highest created monads, as are humans, have besides perception, appetite, "memory" and sensitivity what Leibniz calls apperception, the capacity of reflection. They may have insight in necessary and eternal truths, abstract concepts, "laws of nature", mathematical, logical and metaphysical concepts and truths. These capacities grant them a community with $\operatorname{God}^{14}$. Spirits are the primer candidates for having wellfounded or chimerical phenomena. From now on, concerning phenomena, only spirits are investigated ${ }^{15}$. Leibniz argues in his Nouveaux essais that human spirits have idées innées. That means, the mind is not a tabula rasa receiving ideas from "outside", ideas are "in the mind" from the start. This does not mean, however, that the mind always reflects on them. Among ideas, there are several sorts: necessary ideas, contingent ideas, necessary and contingent truths. With a focus to innate ideas, i.e., humans and their ideas, there are intellectual ideas and sensitive (sensual) ideas ${ }^{16}$. For explicating phenomena, sensitive ideas play an important role.

\subsection{Wellfounded Phenomena}

Sensitive ideas are the ideas which are the "content" of sensitive states of the respective monad. And, being so, they contribute to the identity and determinateness of the monad. They play an ontological role. But, they play a psychological role, too. They can be thought by finite beings, in most cases confusedly. And, for finite beings, they are innate. As Leibniz puts it, they do not stem "from the senses", but they are thought, when sensual modifications are present or memorized:

“Th. [...] Mais les idées qui viennent des sens sont confuses, et les verités qui en dependent, le sont aussi, au moins en partie; au lieu que les idées intellectuelles et les veritées qui en dependent, sont distinctes, [...]"17

But, to be precise:

“Th. [...] C’est assez que ce qui est dans l'entendement y puisse estre trouvé et que les sources ou preuves originaires des verités dont il s'agit, ne soyent que dans

14 See Gerhardt 1965b, III, p. 623.

15 It is an exegetical problem whether and when in his life Leibniz attributes phenomena to beasts. Kulstad 1991 , devotes a monography to this topic.

16 For a detailed interpretation of the different concepts of ideas in Leibniz, see Burkhardt 1980

17 Leibniz 1959, Nouveaux essais, first book, p. 32. 


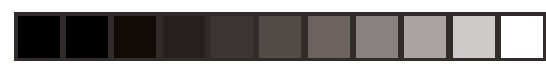

12

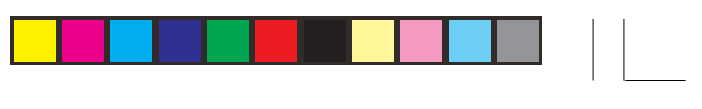

Christina Schneider

l'entendement: les sens peuvent les insinuer, justifier, et confirmer ces verités, mais non pas demonstrer la certitude immanquable et perpetuelle.”18

Intellectual ideas, in contrast, can be thought without actual sensual modification; they are thought when spirits are thinking about logic, mathematics or metaphysics. Since phenomena are, inter alia, sensual experiences, the next task is to differentiate the role of sensitive ideas and sensual modifications without accompaning reflections and apperceptions.

\subsubsection{On Apperception and phenomena}

The part of sensual experience which could be conceived of as purely physiological or physical together with an unreflected "feeling", as could have dogs or horses as well, may be called sensual states. But, since so far there are only monads, perceptions, appetite and coordinated ideas in the Leibnizian world, there cannot be anything else than the respective monad with that part of its complete concept which does not encompass any sort of reflection. The intuition behind what follows is that a simple apperception (apperceptions of apperceptions of apperceptions ... are not dealt with in this paper, since a reflection on a phenomenon, what ever it may be, is not a phenomenon) is the intellectual answer of a spirit to its monadic, physical and sensitive states. Generally, these states do not obtain at the same instance as the apperception takes place, for instance apperceptions about mathematical insights or lawful generalizations in physics are not bound to specific sensitive states. But, phenomena are bound to the monadic, physical and sensitive state the apperceiving monad is in, i.e. to one $t$ in its respective history. Therefore, if the complete concept of a monad instantaneously encompasses apperception about sensual ideas which are bound to an instantaneous perception, a phenomenon comes up. This phenomenon may be wellfounded or not. What has been informally said is: at each instant the complete concept of a spirit encompasses ideas of space and time, sensitive ideas and the blackbox of apperceptions, which has been written as

For the present purpose, sensitive ideas are of interest. Since they are here to "refine" the monadic world and since they complement the monadic/perceptual circumstances the monad in question is in, they must be related to perceptions. This can be written as the mapping $\rho^{s}:\left\{W_{\Phi^{u}(t)}\right\} \rightarrow\left\{a_{\Psi, t, c}^{s}\right\}$, which coordinates a specific perception of the monad in question to its sensitive ideas and can be called "sensual state" of the monad. For simple monads, this state can be empty. For apperceiving monads, the intellectual answer are sensitive

18 Ibid., p. 30. 

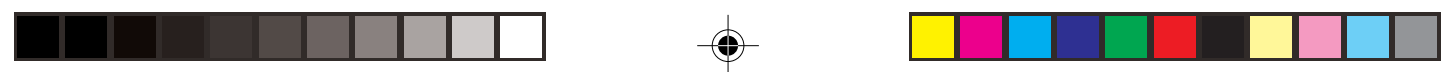

ideas. Usually, sensitve ideas are not apperceived distinctly by finite beings. Only God contemplates them with greatest distinctness. He contemplates them as they are and as they contribute (ontologically) to the sensitive state of the respective monad. Let $S$ be the set of simple sensual ideas "in God's mind" and let $\mathbf{S}$ be a set of subsets of $S$ (including sets which give rise, for instance, to the universals contemplated by finite beings), then an apperception of the sensual state the apperceiving monad is in may be written as a partial mapping

$$
k_{\Psi, t, c}: a_{\Psi, t, c}^{s} \rightarrow \mathbf{S}
$$

Strictly speaking, the mapping should have the respective instantaneous monad as well as the covariating "ideas of space and time" as source, but since by preestablished harmony $a_{\psi, t, c}^{s}$ covariates with them (by $\rho$ ), the sensitve ideas are sufficient as source.

is a partial mapping, since not every sensitive idea coconstituting the monad/individual may be coordinated by an apperceived idea. An apperceived idea is a set of simple ideas in God's mind. The apperception is the partial mapping. The elements of the image of the apperception can be conceived of the content of the apperception. They make up what is apperceived.

To sum up, a phenomenon is a special sort of apperception. It is an apperception which relates only to instantaneous states of monads which only perceive parts of the monadic world and which has only sensitive ideas as "content". So far, there was no mentioning whether such a phenomenon is wellfounded or not. The next paragraph focusses on this question.

\subsubsection{Wellfoundedness}

The wellfoundedness of a phenomenon means that the content of the respective phenomenon has something to do with the monadic neighborhood of the respective apperception as well as with the senstive states, specifically the coconstituting sensitive ideas $a_{\psi, t, c}^{s}$, with which the phenomenon is coordinated. In a first step, concerning the ideas which constitute $a_{\psi, t, c}^{s}$, wellfoundedness means that the ideas of $\mathbf{S}$ which are contemplated include at least some of the constituting sensitive ideas of the complete concept of the instantaneous monad: A phenomenon is ideally wellfounded iff there exists an $S_{i} \in k_{\psi, t, c}^{s}\left(a_{\psi, t, c}^{s}\right)$ with $a_{\psi, t, c}^{s} \cap S_{i} \neq \varnothing$.

Since the sensitive ideas constituting a monad/individual are naturally coordinated with the monadic realm, the definition of a monadically wellfounded phenomenon, short: wellfounded phenomenon, is straightforeward. One must just remember that the sensitive ideas of the complete concept are coordinated with a respective perception by the mapping $\rho^{s}$ which expresses the sensual state a monad is in: $\rho^{s}:\left\{W_{\Phi^{u}(t)}\right\} \rightarrow\left\{a_{\Psi, t, c}^{s}\right\}$. 


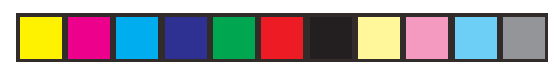

14

Christina Schneider

Since a perception is always the perception of other monads, the monadic foundation of a wellfounded phenomena are all the monads the perception in question perceives. Formally: the monadic foundation for an ideally wellfounded phenomenon is

$$
\left\{\left(\mathbf{W}_{\Phi^{u^{\prime}}(t)}, t \in \mathfrak{R}\right): u^{\prime} \in W, \exists t^{\prime} \Phi\left(u^{\prime}, t^{\prime}\right) \in W_{\Phi^{u^{\prime}}(t)}\right\}
$$

This is obviously a set of monads, or informally, an aggregate of monads. Therefore, a wellfounded phenomenon is a special apperception whose wellfoundedness roots, on the one hand, in the coordination of the constituting sensitve ideas of the apperceiving monad and, on the other hand, in an aggregate of other monads. But, there cannot be a "monadically wellfounded phenomenon" that is not ideally wellfounded.

\subsection{Bodies are wellfounded phenomena and monadic aggregates}

The solution of the puzzle appears now to be rather simple: Since a body is a phenomenal entity, it is wellfounded, if the apperceived ideas, which are the intelligble content of the phenomenenon, are coordinated with a monadic aggregate which is the monadic foundation of the phenomenon. This coordination holds, if the sensitve ideas of the respective sensitive state intersect the apperceived sensitive ideas.

\section{What are the insights of Leibniz's theory?}

Leibniz is a systematic thinker. This means, strictly speaking, that accepting one of his more special theories amounts to accepting the whole frame of his metaphysics. Concerning the present topic, his theory of bodies and of wellfounded phenomena, this means: In a strict sense, one cannot accept his theory of bodies without accepting his theory of ideas in the mind of God, his theory of monads, and his theory of apperception. Since all these theories derive from his theory of God and God's generation of the world, these theories had to be accepted also. To assess the acceptability of these great topics cannot be the issue of a concluding remark, the question "What are the insights of Leibniz's theory?” is addressed more modestly. Only some few aspects will be sketched.

Leibniz's terminology certainly is outdated in many respects. His conception of what he calls "ideas" and configuration thereof is a rather simple combinatorial scheme. His talk of monads and perceptions and the metaphors he offers to explain them, like "mirroring", for instance, may cause some problems for modern philosophers. Now, these metaphysical realms and entities are conceived of in a wider understanding. The word "ideas" is taken as 

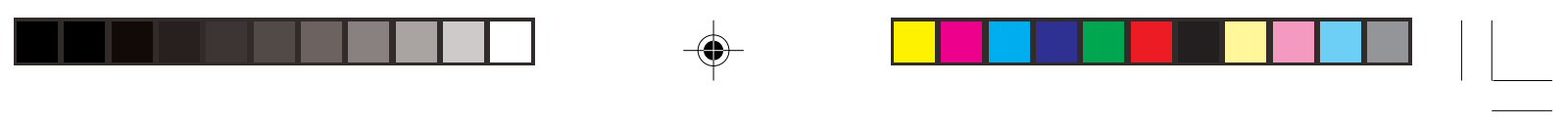

a generic word for "intelligible contents", which can be thought of and which have also an ontological status. The monadic realm as a metaphysical region, what ever it may be otherwise, is understood as being not "ideal" but complementing the ideal realm. With this restrictions, some few insights can be worked out.

The core of Leibniz's theory of bodies is his theory of wellfounded phenomena. And, irrespective of several interpretations or reconstructions, this theory says: All those entities nowadays called "middle-sized objects", as well as space, time and matter are phenomena. This means, besides being ideal in some sense, that they have existence only as contents of apperception (sensitivity). If they are "real" — i.e., wellfounded — beyond being contents of apperception, this is in virtue of being coordinated to "ideas" and monads. As a consequence, without apperceiving (and sensitive entities), space, time and matter would not be anything else but a special geometry coordinated to "another realm". Or, in a world without living beings, there would not be any coulors, as red green or orange. There would be special wavelengths. The analog holds for all so called "secondary qualities". This is a philosophical stance which may conflict with several normal intutions, but this does not mean that it is wrong or not defensable. Since "world" is a highly komplex definite structur in Leibniz, even if there are no apperceiving entities, "worldmaking-philosophies" and anthropocentric theories to come to grips with the intelligibilty of "the world" are avoided. Moreover, Leibniz's attempt furnishes a first step in explainig why different apperceiving beings may have different concepts of the same portion of "the world" which may, nevertheless, all be "true" to the portion of "the world" in question: the concepts used for description may be coarser than the ontologically primer ideas. For analogy: to say of the number 2 that it is a positive number is "true", to say that it is a prime number is "true" also: it is both, and many more "truths" may be said about it. The number 2 is not anything over and above all obtaining ideas connected with it.

There is a wider problem Leibniz's theory of wellfounded phenomena hints at: If the monadic world is structured or if it is a structure, in what sense is it "not ideal"? If it is not structured or if it contains unstructured "regions", what are they? If one can truely locate or explain them, there must something intelligibel about them, in Leibniz's frame, they must be ideal. If not, the words used to indicate these structureless and unexpressable regions are hardly intelligible. Is there any systematic need for a non-ideal realm? Mutatis mutandis the same holds for apperception: What is it about apperception which is not ideal? Certainly not the contents, not what is apperceived of primer apperceptions. What is more about apperception than being a highly complex 
substructur of the idées innées, to use a Leibnizean term? Is there any "entity" over and above special substructures of ideas to complete what can be called "apperception"? If there is, is it expressable and intelligible or not? The questions addressed above are farreaching ones: They hint, for instance, to problems in metaphysical/philosophical category theory and to problems concerning the philosophical theory of God. But they are not germaine to Leibniz. Leibniz's metaphysics, however, is rich and sophisticated enough, to isolate the "big problems" and to give hints how to overcome them.

\section{References}

Adams, R. M.: 1983, "Phenomenalism and Corporeal Substance in Leibniz". Midwest Studies in Philosophy, VIII, pp. 217-257.

Burkhardt, H.: 1980, Logik und Semiotik in der Philosophie von Liebniz. Philosophia Verlag, München.

Gerhardt, C. I. (Ed.): 1965a, G. W. Leibniz. Die philosophischen Schriften, I-VII. Olms Verlagsbuchhandlung, Hildesheim.

Gerhardt, C. I. (Ed.): 1965b, G. W. Leibniz. Die mathematischen Schriften, I-VII. Olms Verlagsbuchhandlung, Hildesheim.

Kelley, J. L.: 1955, General Topology. D. van Nostrand Company, Toronto-New YorkLondon.

Kulstad, M.: 1991, Leibniz on Apperception, Consciousness, and reflection. Philosophia Verlag, München.

Leibniz, G. W.: 1959, Nouveaux essais sur l'entendement humain. Wissenschaftliche Buchgesellschaft, Darmstadt. 2 volumes, French text and German translation by W. v. Engelhardt and H. H. Holz.

Mormann, T.: 1995, “Trope Sheaves: A Topological Ontology of Tropes”. Logic and Logical Philosophy, 3, pp. 129-150.

Rutherford, D.: 1995, Leibniz and the Rational Order of Nature. Cambridge University Press, Cambridge.

Schneider, C.: 1998, "Leibniz’s Theory of Space-Time: An Apporach from His Metaphysics”. The Monist 81, pp. 612-632.

Schneider, C.: 1999, Ein formaler Zugang zu Leibniz'Metaphysik. PhD dissertation, University of Munich 1999.

Strawson, P. F.: 1959: Individuals. An Essay in Descriptive Mtaphysics. Methuen, London.

Wilson, C.: 1989, Leibniz' Metaphysics - The Concept of Substance in Seventeenth Century Metaphysics. Princeton University Press, Princeton, N. J.

e-mail:christin@stat.uni-muenchen.de 